\title{
The Effect of Hypervelocity Impact Loading on Explosively Welded Ti/Al/Al Plate
}

\author{
Marcin Wachowski ${ }^{1, a}$, Teresa Fras ${ }^{2}$, Robert Kosturek ${ }^{1}$, Lucjan Śnieżek ${ }^{1}$, Ireneusz Szachogłuchowicz ${ }^{1}$ \\ and Krzysztof Grzelak ${ }^{1}$ \\ ${ }^{1}$ Military University of Technology, Faculty of Mechanical Engineering, 2 gen. W. Urbanowicza str., 00-908 Warsaw, \\ Poland \\ ${ }^{2}$ French-German Research Institute of Saint-Louis (ISL), 5 rue du General Cassagnou, 68301 Saint-Louis, France
}

\begin{abstract}
The aim of this paper is to investigate the ballistic properties of explosively welded Ti6A14V/AA1050/AA2519 laminate under hypervelocity $(4000 \mathrm{~m} / \mathrm{s})$ impact loading of projectile made of aluminium ball. The paper describes the influence of the projectile impact energy on the structure of the laminate components and delamination of bonds depending on its strength and presence of intermetallic phases. Observation of the failure is performed for the plate impacted for aluminium alloy side. Results revealed ductile shearing as a dominant process leading to perforation.
\end{abstract}

\section{Introduction}

One of the most promising engineering materials in terms of the improvement ballistic properties of shields used in space environmental constructions are metallic laminates [1-3]. The main problem of the construction stays in space is presence of debris, cosmic dust and trashes e.g. parts of old satellites which travel with very high speed often exceed thousands of meters per second. These elements constitute main threat for space stations and satellites because potential collisions can cause significant damage of construction. Currently applied shields protecting against debris consist of several very thick layers of aluminium alloy. Additionally, each layer is separated to reduce the fragmentation phenomenon. The approach that is worth consideration is using laminates to provide the necessary ballistic properties with ensured the lowest weight and thickness of the shield used in space constructions. One of the most interesting metallic laminate which fully satisfies these requirements is aluminium alloy AA2519 - titanium alloy Ti6A14V laminate. The appropriate technology to clad aluminium alloy with high strength titanium alloy is explosive welding method [4-7]. To obtain explosively welded joint between Ti6Al4V and AA2519 applying additional interlayer made of aluminium alloy AA1050 was necessary. Explosive welding is a solid-state welding technology which allows to create a metallic bond between two metal surfaces by the energy of detonation of high explosive material [8-11]. Harsh conditions of the process influence on bond zone and base materials causing their hardening and present of intermetallic phases in the joint. Presence of very hard and brittle intermetallic zones adjacent to the joint significantly increase of ballistic properties of the whole laminate [12-15]. The presented paper discusses ballistic properties of the explosively welded

\footnotetext{
${ }^{\mathrm{a}}$ Corresponding author : marcin.wachowski@ wat.edu.pl
} 
Ti6Al4V/A1050/AA2519 plates impacted by aluminium ball accelerated to hypervelocity equal 4000 $\mathrm{m} / \mathrm{s}$. Investigated laminate is considered as an armour in space application. In the performed investigation aluminium ball projectile accelerated to hypervelocity condition is equivalent of debris flying in space which constituting threat for construction in space e.g. satellites, space stations. The microstructure observation and fractography investigation of perforation zone using light microscopy (LM) and scanning electron microscopy (SEM) allows to understand mechanisms of penetration and perforation in explosively-welded layered structures under hypervelocity impact loadings.

\section{Experimental part}

The titanium alloy Ti6Al4V has been successfully cladded with aluminium alloy 1050 and aluminium alloy 2519 by using explosive welding process. As an explosive material, the mixture of ammonium nitrate fuel oil (ANFO) was used. The scheme of the explosive welding system is shown in Figure 1. The thickness of the welded elements was equal to $5 \mathrm{~mm}$ for Ti6Al4V, $5 \mathrm{~mm}$ for AA2519 and $1 \mathrm{~mm}$ for AA1050. Before explosive welding the joined materials are cleaned, degreased and oxides are removed. Explosive welding process was performed by EXPLOMET High-Energy Techniques Works.

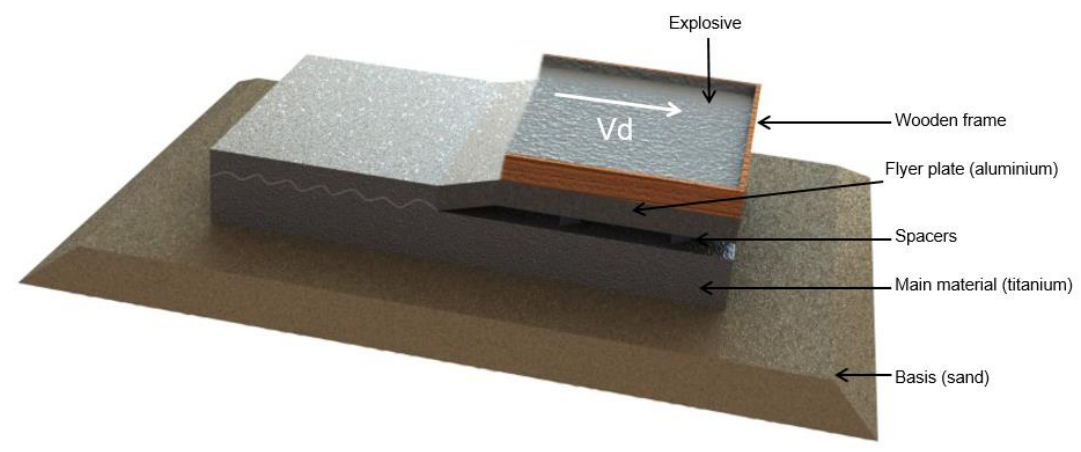

Figure 1. Scheme of explosive welding process. Vd - velocity of explosive detonation.

\section{Results and discussion}

\subsection{Microstructure}

The explosive welding process allowed to obtain high-quality Ti6A14V/AA1050/AA2519 joint. Investigated laminate is characterized by the presence of intermetallic phases in the melted zone adjacent to the Ti6A14V/AA1050 joint (Figure 2). Scanning electron microscopy (SEM) observation revealed flat-shaped joint with lack of delamination and voids. Presence of intermetallic phases and melted zones is the result of the high velocity, high temperature and high pressure generated during collision. SEM observation of AA1050/AA2519 joint revealed characteristic wavy-shape joint with no imperfections, such as cracks and voids. This joint is also characterized by the lack of intermetallic phases. Discrepancy in shape of joints is the results of differences in density and mechanical properties of the joined materials. In the melted zones, the investigation revealed the presence of fragments of Ti6Al4V surface layer, which underwent partial fragmentation during welding process in this area, as evidenced by analysis of titanium and aluminium distribution at the sample surface (Figure 3, Table 1). 

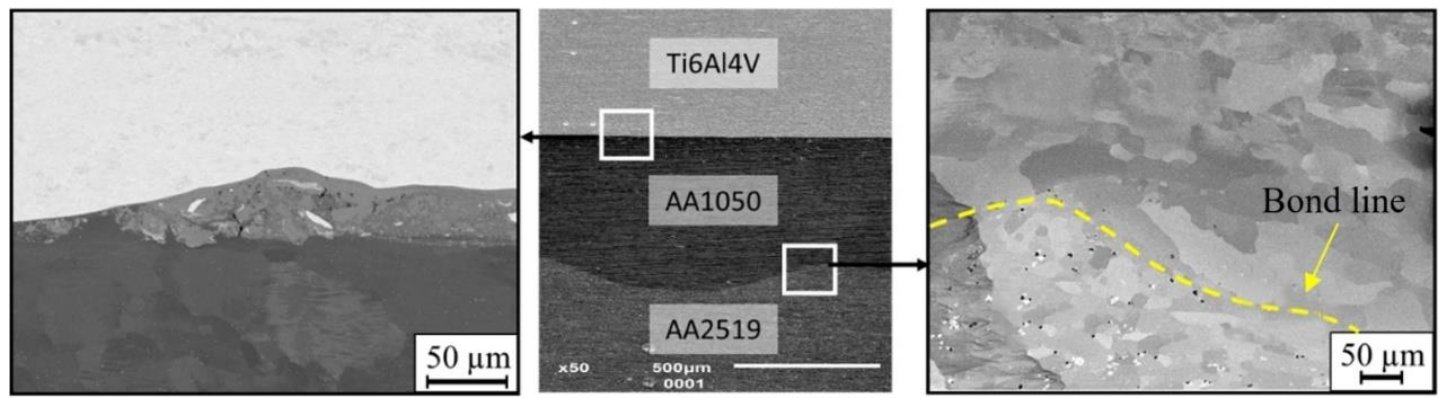

Figure 2. Microstructure of the laminate components.

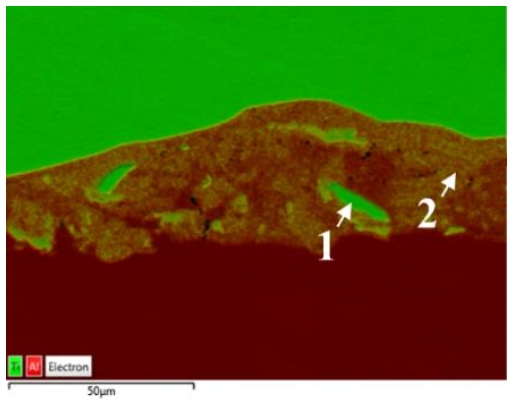

Figure 3. Microstructure of the Ti6A14V/AA1050 joint.

Table 1. EDX mapping of the Ti6Al4V/AA1050 joint.

\begin{tabular}{|c|c|c|}
\hline Point & \multicolumn{2}{|c|}{ Chemical composition \% weight } \\
\hline & $\mathrm{Al}$ & $\mathrm{Ti}$ \\
\hline 1 & 6.5 & 93.5 \\
\hline 2 & 64.4 & 35.6 \\
\hline
\end{tabular}

\subsection{Hypervelocity Ballistic Impact Test}

The cross-sections of the sample revealed that the projectile impact caused a large deformation of the plates and a delamination between AA1050 aluminium and Ti6Al4V layers. Ballistic research results revealed penetration of the projectile through AA2519 plate. Diameter of the resulting crater was about $55 \mathrm{~mm}$. SEM images of the titanium and aluminium (Figure 4) depict smooth surfaces, which reveal that the ductile shearing is as a dominant process leading to perforation. In the first impact stage, a part of the energy of the projectile was acquired by the AA2519 plate. The result of this process is the dispersion and deceleration of the shock wave. The slower spread of impact energy in the material causes the formation of the crater neck due to frontal petalling process of AA2519 alloy. During the penetration, the moving projectile pushed the structure directly below its nose, which caused stretching of the laminate layers. In Ti6Al4V/AA1050 joint has been delaminated during the shooting (Figure 5). Delamination indicate that the material has reached the maximum strength limit due to perforation with the projectile and is a result of absorption of the generated energy due to the partial reflection of the shock wave from the titanium alloy. This effect minimizes the phenomenon of generating debris in the space due to the plastic deformation of the material on a larger surface. Delamination, therefore, is a phenomenon that positively affects the improvement of the ballistic properties of the produced laminate. A phenomenon favouring the delamination of Ti6Al4V/AA1050 joint is the process of partial reflection of the shock wave at the boundary of materials with two different densities. As a result, the primary shock wave loads the material towards the titanium and the 
reflected wave causes stretch of the joint in the opposite direction. Therefore, the joint is stretched in two opposite directions, what causes the occurrence of high shear stresses in the joint surface.
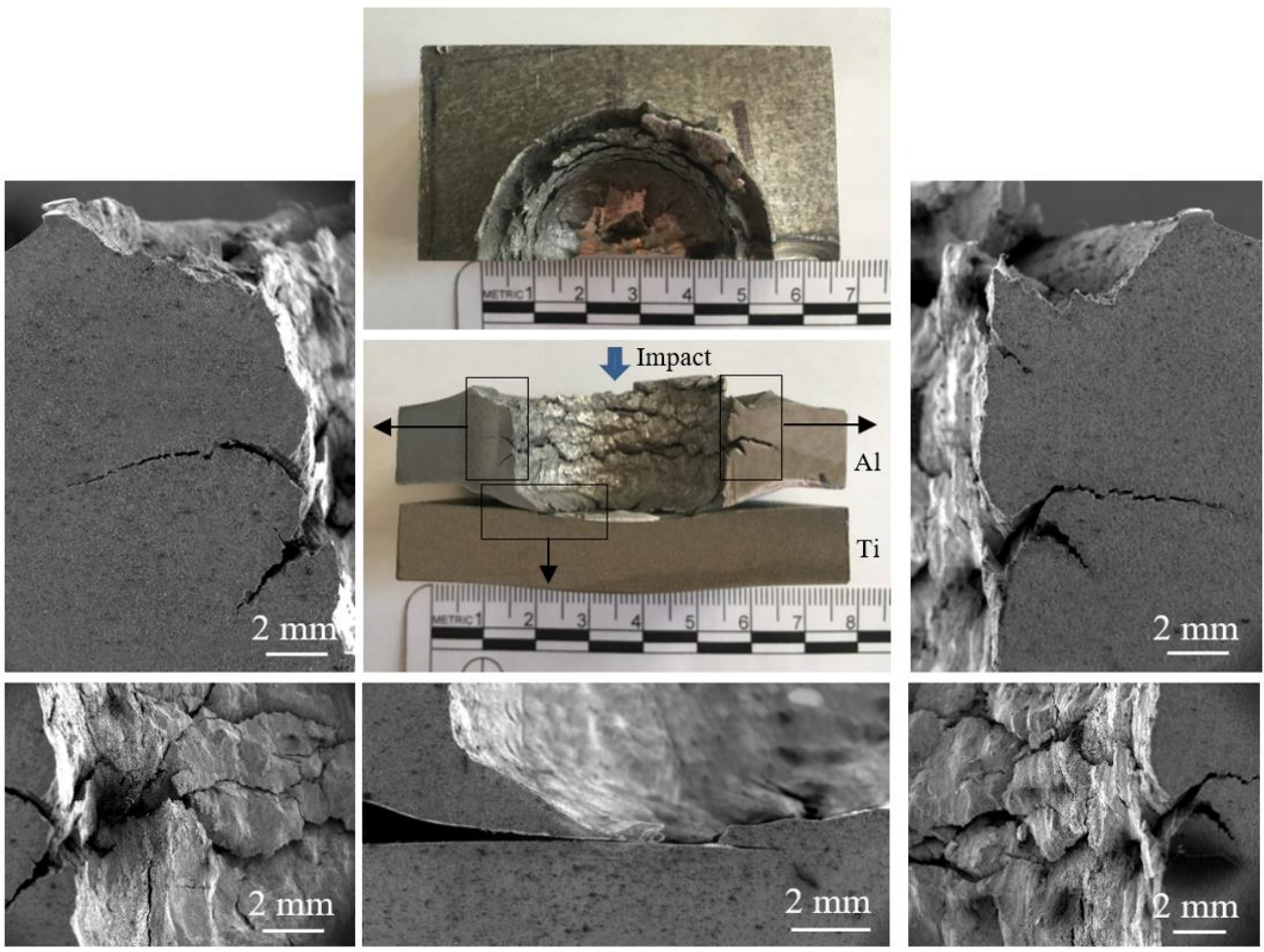

Figure 4. Fractography observation of the specimen after hypervelocity impact test.

The performed investigations showed that delamination occurs only in the Ti6Al4V/AA1050 joint (Figure 5A) and in case of AA1050/AA2519 joint despite the severe deformation due to ballistic load the cohesion of the materials bound is preserved (Figure 5B). The main reason of this phenomenon is the fact that in contrast to Ti6Al4V/AA1050 joint the joint between two aluminum alloys is free of intermetallic phases. The Ti6A14V/AA1050 joint surface is characterized by presence of brittle phases from Ti-Al system, which tend to crack during dynamic load and therefore cause the breaking of cohesion between two plates.
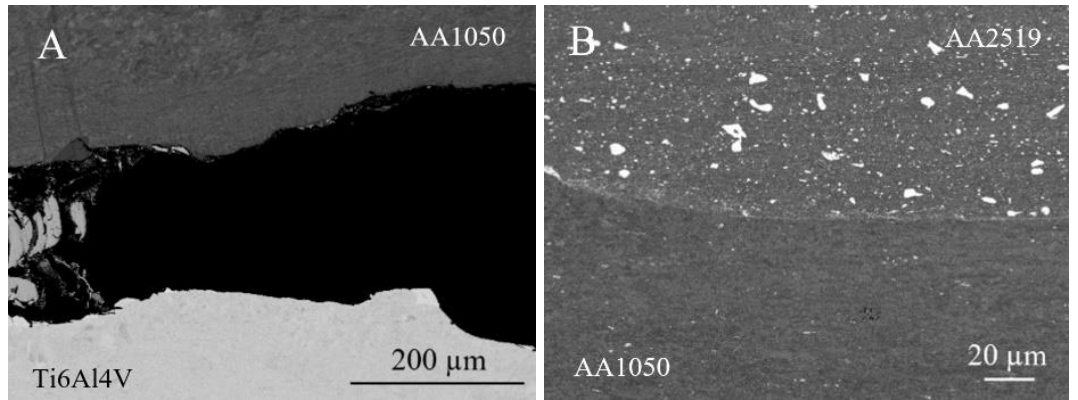

Figure 5. SEM observation of the specimen after hypervelocity impact test.

A) Ti6A14V/AA1050 joint, B) AA1050/AA2519 joint

\section{Conclusions}


Explosive welding of aluminum alloy AA2519 with high strength titanium alloy Ti6Al4V using interlayer AA1050 allows to obtain a good quality joints free of cracks and voids, with the participation of melted zones and intermetallic phases between titanium alloy and aluminum AA1050. The ballistic performance of a Ti6Al4V/AA1050/AA2519 laminate was investigated in ballistic test to observe failure mechanism of material under hypervelocity conditions of impact. Result revealed that laminate is well suited to ballistic protection applications because of the combination of the material properties and structure of their constituents. The delamination, which took place on the surface of Ti6Al4V/A1050 joint has been caused by presence of the brittle intermetallic compounds localized in the melted zone on the joint interface. Fractography observation revealed that the ductile shearing is as a dominant process leading to perforation through the laminate components. Delamination of Ti6Al4V/AA1050 joint is results of the simultaneous impact of the falling impact wave and the shock wave reflected from the boundary of materials with two different densities.

\section{Acknowledgments}

This work uses results of the research from the project co-financed from Polish Ministry of National Defence No. PBG/13-998. This work was also supported by the Project PBS2/A5/35/2013 funded by the National Research and Development Centre.

\section{References}

1. I. Crouch, The Science of Armour Materials (Woodhead Publishing 2016).

2. H. Gower, D.S. Cronin, A. Plumtree, Inter. J. of Imp. Eng. 35, 1000-1008 (2008).

3. M. Übeyli, Y. Orhan, B. Ögel, Mat. \& Des. 28, 1257-1262 (2007).

4. D. Boroński, M. Kotyk, P. Maćkowiak, L. Śnieżek, Mat. \& Des. 133 (2017).

5. P. Bazarnik, B. Adamczyk-Cieślak, A. Gałka, B. Płonka, L. Śnieżek, M. Cantoni, M. Lewandowska, Mat. \& Des. 111 (2016).

6. P. Bazarnik, M. Cantoni, L. Śnieżek, M. Lewandowska, European Microscopy Congress 2016: Proceedings, (Poland, 2016)

7. L. Śnieżek, I. Szachogluchowicz, M. Wachowski, J. Torzewski, J. Mierzynski, Proc. Str. Int. 5, 422-429 (2017).

8. T.Z. Blazynski, Explosive Welding, Forming and Compaction, Applied Science (1983).

9. F. Findik, Mat. \& Des. 32, 1081-1093 (2011).

10. R. Kosturek, M. Najwer, P. Nieslony, M. Wachowski, Adv. in Man., 681-686 (2018).

11. S.A.A Akbari Mousavi, L.M. Barrett, S. Al-Hassani, J. of Mat. Proc. Tech. 202. 224-239 (2008).

12. D.M. Fronczek, R. Chulist, L. Litynska-Dobrzynska, G.A. Lopez, A. Wierzbicka-Miernik, N. Schell, Z. Szulc, J. Wojewoda-Budka, Metall. and Mat. Trans. A 48, 4154-4165 (2017).

13. G.H.S.F.L. Carvalho, I. Galvão, R. Mendes, R. Leal, A. Loureiro, Mat. Ch. 142, $432-442$ (2018).

14. D.M. Fronczek, R. Chulist, Z. Szulc, J. Wojewoda-Budka, Growth kinetics of TiAl3 phase in annealed Al/Ti/Al explosively welded clads, Mat. Let. 198, 160-163 (2017).

15. B. Greenberg, M. Ivanov, M. Pushkin, A. Inozemtsev, A. Patselov, A. Tankeyev, S. Kuzmin, V. Lysak, Met. and Mat. Tran. A 47, 5461-5473 (2016). 